\title{
The role of bariatric surgery on kidney transplantation: A systematic review and meta- analysis
}

Yung Lee, MD ${ }^{1}$; Lucshman Raveendran, $\mathrm{BHSc}^{2}$; Olivia Lovrics, $\mathrm{MSc}^{1}$; Chenchen Tian, $\mathrm{BHSc}^{2}$; Adree Khondker, BHSc ${ }^{2}$, Martin A. Koyle, MD, MSc ${ }^{3}$; Monica Farcas, MEng ${ }^{4}$; Aristithes G. Doumouras, MD, $\mathrm{MPH}^{1}$; Dennis Hong, $\mathrm{MD}, \mathrm{MSc}^{1}$

${ }^{1}$ Division of General Surgery, McMaster University, Hamilton, ON, Canada; ${ }^{2}$ Faculty of Medicine, University of Toronto, Toronto, ON, Canada; ${ }^{3}$ Division of Pediatric Urology, Hospital for Sick Children, Toronto, ON, Canada; ${ }^{4}$ Division of Urology, Department of Surgery, St. Michael's Hospital, University of Toronto, Toronto, ON, Canada

Cite as: Lee Y, Raveendran L, Lovrics O, et al. The role of bariatric surgery on kidney transplantation: A systematic review and meta-analysis. Can Urol Assoc J 2021 March 18; Epub ahead of print. http://dx.doi.org/10.5489/cuaj.7109

Published online March 18, 2021

$* * *$

\begin{abstract}
Introduction: Obesity (body mass index $[\mathrm{BMI}]>35 \mathrm{~kg} / \mathrm{m}^{2}$ ) remains a relative contraindication for kidney transplant, while patients after kidney transplantation (KTX) are predisposed to obesity. The present study aims to investigate the role of bariatric surgery in improving transplant candidacy in patients prior to KTX, as well its safety and efficacy in KTX patients postoperatively.
\end{abstract}

Methods: A systematic search was conducted up to March 2020. Both comparative and noncomparative studies investigating the role of bariatric surgery before or after KTX were considered. Outcomes included change in BMI, rates of mortality and complications, and the rate of patients who underwent KTX following bariatric surgery. Pooled estimates were calculated using the random effects meta-analysis of proportions.

Results: Twenty-one studies were eligible for final review; 11 studies investigated the role of bariatric surgery before KTX. The weighted mean BMI was $43.4(5.7) \mathrm{kg} / \mathrm{m}^{2}$ at baseline and $33.9(6.3) \mathrm{kg} / \mathrm{m}^{2}$ at 29.1 months followup. After bariatric surgery, 83\% (95\% confidence interval [CI] 57-99) were successfully listed for KTX and 83\% (95\% CI 65-97) patients subsequently received successful KTX. Ten studies investigated the role of bariatric surgery after kidney transplant. Weighted mean baseline BMI was $43.8(2.2) \mathrm{kg} / \mathrm{m}^{2}$ and mean BMI at 19.5 months followup was $34.2(6.7) \mathrm{kg} / \mathrm{m}^{2}$. Overall, all-cause 30 -day mortality was $0.5 \%$ for both those who 
underwent bariatric surgery before or after receiving a KTX. The results of this study are limited by the inclusion of only non-randomized studies, limited followup, and high heterogeneity. Conclusions: Bariatric surgery may be safe and effective in reducing weight to improve KTX candidacy in patients with severe obesity and can also be used safely following KTX.

\section{Introduction}

The prevalence of obesity and its associated comorbidities such as type 2 diabetes mellitus (T2DM), dyslipidemia, and hypertension have been rising globally. ${ }^{1,2}$ Consequently, obesity and its associated comorbidities has been found to independently negatively affect kidney function. ${ }^{3,4}$ Considering this, the population is at higher risk for requiring transplantation; however, the effect of obesity on kidney transplant (KTX) outcomes is equivocal and controversial. Consensus guidelines released by the Canadian Society of Transplantation recommend that obesity alone should not be a contraindication for KTX while also recommending that patients with obesity undergo a supervised weight loss program to achieve a target BMI $<30 \mathrm{~kg} / \mathrm{m}^{2}$ in order to mitigate the risks of transplantation. ${ }^{5}$

Numerous studies have demonstrated the negative effects of obesity on KTX outcomes, including significantly higher rates of delayed graft function. ${ }^{6,7}$ Obesity may also confer increased operative time, rates of acute graft rejection, rates of new onset diabetes after transplant, and worse graft survival post-KTX. ${ }^{6-13}$ Thus, in the United States, Class II obesity or higher (body mass index (BMI) $\geq 35 \mathrm{~kg} / \mathrm{m}^{2}$ ) is an often used as a contraindication for KTX due to observed increased rates of perioperative and post-operative complications and poorer patient outcomes. ${ }^{14,15}$ Finally, obesity has been associated with increased all-cause mortality and cardiovascular disease-related deaths in the KTX populations. ${ }^{6,16,17}$

In spite of these increased risks of graft failure, patients with obesity may still be evaluated for and subsequently undergo KTX, as the survival and quality of life benefits of KTX often outweigh the associated risks and the benefits of dialysis. ${ }^{15}$ Data from the United Network for Organ Sharing up to March 2011 demonstrated that $29.7 \%$ of the 74,983 KTX recipients had obesity. ${ }^{18}$ Additionally, KTX predisposes the recipient to developing obesity owing to the chronic use of corticosteroids, alterations in leptin levels and appetite, and post-transplant lifestyle changes. ${ }^{19,20}$ The ensuing weight gain has been linked to poorer transplant outcomes, including graft rejection and increased mortality. 4,19

Weight loss can improve glomerular filtration rate and proteinuria, resolve comorbidities, and reduction in medication load. ${ }^{4,19}$ However, medical weight loss slow and ineffective, especially in the kidney failure population. ${ }^{21,22}$ While bariatric surgery has been shown to be the most effective treatment for morbid obesity, ${ }^{22,23}$ it is only now starting to be recommended to patients with obesity who require transplantation and is not yet widely adopted as a treatment 


\section{Review: Bariatric surgery and kidney transplant}

option for severe obesity in these populations. ${ }^{7,13,24}$ Differences exist in the literature on the utility of bariatric surgery to induce substantial weight loss prior to transplantation, resulting in improved suitability for KTX and the potential alleviated risks of high BMI on KTX outcomes. ${ }^{4,14}$ Finally, while bariatric surgery has been proven safe and effective, the benefits of bariatric surgery in the post-KTX patient has not been definitively shown.

KTX offers longer survival and better quality of life compared to other treatment modalities for chronic kidney disease and kidney failure, such as dialysis, and thus, it is paramount to optimize the accessibility to and outcomes of KTX in patients with and without obesity. ${ }^{25-30}$ The present study aims to investigate the role of bariatric surgery in improving transplant candidacy in patients prior to KTX, as well its safety and efficacy in KTX patients in the postoperatively.

\section{Methods}

\section{Search strategy}

We searched the following databases covering the period from database inception through March 2020: MEDLINE, EMBASE, CENTRAL, PubMed, and Web of Science. The search was designed and conducted by a medical librarian with input from study investigators. The search strategy included keywords relating to bariatric surgery and KTX (complete search strategy available in Appendix 1). We also searched the references of published studies and searched grey literature manually to ensure that relevant articles were not missed. We did not discriminate full texts by language. This systematic review and meta-analysis is reported in accordance with the Preferred Reporting Items for Systematic Reviews and Meta-Analyses (PRISMA). ${ }^{31}$

\section{Outcomes}

For studies that conducted bariatric surgery before KTX, primary outcomes were: 1) number of patients successfully listed for transplant after bariatric surgery; 2) number of patients that successfully received transplant; 3) all-cause 30-day mortality after bariatric surgery. For studies that conducted bariatric surgery after transplant, the primary outcome was all-cause 30-day mortality after bariatric surgery.

Secondary outcomes for both types of studies were: 1) 30-days minor complication and 30-days major complications after bariatric surgery; 2) graft failure (i.e. return to dialysis) after bariatric surgery; 3 ) weight change after bariatric surgery; 4) type remission of type 2 diabetes (i.e. discontinuing antidiabetic drugs or insulin) and/or hypertension (i.e. discontinuing antihypertensive drugs) after bariatric surgery as defined by individual study criteria. Major complications were classified as Clavien-Dindo complication classification grade III or above (conditions requiring surgical, radiological, and endoscopic intervention, organ dysfunction, or death) and minor complications were defined as conditions such as wound infections, diarrhea, abdominal discomfort. ${ }^{32}$ 


\section{Review: Bariatric surgery and kidney transplant}

\section{Eligibility criteria and data abstraction}

We included both non-comparative studies and comparative studies investigating the role of bariatric surgery before or after KTX in patients meeting standard criteria for bariatric surgery (BMI $>40$, or BMI $>35$ with obesity-related complications). Exclusion criteria was: 1) studies where patients did not meet standard criteria for bariatric surgery; 2) basic science, case-reports, and review articles; 3) nonhuman studies 4) studies with no relevant outcome of interest.

Two reviewers independently screened the titles and abstracts of articles identified through the search strategy. Discrepancies in the title and abstract stage were resolved by automatic inclusion to ensure that all relevant articles were not missed. Discrepancies at the fulltext or data abstraction stage were resolved by consensus between 2 reviewers, and if disagreement persisted, a third reviewer was consulted. Two reviewers independently extracted relevant data on patient characteristics and outcomes at the full-text level. Data was inputted on a standardized spreadsheet designed a priori. Disagreement between reviewers were also solved by consensus or by a third reviewer.

We extracted the following variables from each study: year of publication, study design, number of patients, type of bariatric procedure, characteristics of patients before and after bariatric surgery (gender, age, body mass index, percent excess weight loss (\%EWL), comorbidities of patients before and after bariatric surgery (e.g. type 2 diabetes, hypertension, dyslipidemia, obstructive sleep apnea), any reported complications, and mortality after bariatric surgery, and KTX-related information (e.g., indications for KTX, time from bariatric surgery to KTX, complications). Patient comorbidities and anthropometric data was captured at multiple time points after bariatric surgery in the event the study reported on patients at multiple followup time intervals.

\section{Statistical analysis}

All statistical analysis and meta-analysis were performed on STATA, version 14 (StataCorp, College, TX) and Cochrane Review Manager 5.3 (London, United Kingdom). The threshold for statistical significance was set $a$ priori at alpha $=0.05$. The pooled proportion of KTX outcomes before and after bariatric surgery was calculated using the Freeman-Tukey double arcsine transformation of proportions. DerSimonian and Laird random effects meta-analysis of proportions was used to generate the overall effect size of each outcome. We performed pairwise meta-analyses using a DerSimonian and Laird random effects model for continuous variables before and after bariatric surgery. Pooled effect estimates for continuous variables were obtained by calculating the mean difference and dichotomous variables were obtained by calculating risk ratios along with their respective $95 \%$ confidence intervals $(\mathrm{CI})$ to confirm the effect size estimation. Assessment of heterogeneity was completed using the inconsistency $\left(\mathrm{I}^{2}\right)$ statistic. We considered $\mathrm{I}^{2}$ higher than $50 \%$ to represent considerable heterogeneity. ${ }^{30}$ Herein, pooled means are reported with standard deviation unless otherwise specified. 


\section{Quality assessment of included studies}

Risk of bias assessment for individual studies was conducted using the Methodological Index for Non-Randomized Studies (MINORS) tool. ${ }^{33}$ Two reviewers independently graded the articles based on the twelve-point framework. Discrepancies between reviewers were resolved by consensus and a discussion with a third reviewer if discrepancies persisted.

\section{Results}

\section{Study characteristics}

In total, initial query of electronic databases yielded 3,155 potentially eligible studies. Included studies were divided into two groups on the basis of bariatric surgery timing with respect to KTX: bariatric surgery before KTX, and bariatric surgery after KTX. Based on study inclusion and exclusion criteria, 11 studies $^{34,35,44,36-43}$ were included for the subgroup of bariatric surgery before KTX and 10 studies ${ }^{4,14,15,20,36,45-49}$ were for bariatric surgery after KTX (Figure 1). The characteristics of the included studies are shown in Table 1.

Of the 11 studies examining bariatric surgery before KTX, 6 were retrospective cohort studies and 5 were case series. In total, there were 453 patients that received bariatric surgery before KTX. The mean age was 50.1 (5.1) years. 54.4\% of this cohort was female. The included studies were conducted between 2005 and 2019, with a mean follow-up period of 30.3 (range, 13.6-60) months after bariatric surgery. Indications for KTX were reported 8/11 studies; common indications were diabetic nephropathy $(n=65,37.1 \%)$, and hypertension $(n=23,13.4 \%)$ (Table 2). All 13 indications are listed in Table 2. Bariatric surgeries conducted in the studies were sleeve gastrectomy (SG; 8 studies), laparoscopic adjustable gastric band (LAGB; 4 studies), and Roux-en-Y gastric bypass (RYGB; 4 studies) (number of patients in each surgery group can be found in Table 1).

Of the 10 studies examining bariatric surgery after KTX, there were 6 case series studies, 2 retrospective cohort studies, 1 case-control, and 1 prospective cohort study. These 10 studies include a total of 201 patients who received bariatric surgery after transplant, of whom 53.9\% were female. The mean age of this cohort was 47.4 (10.8) years. The analyzed studies were all conducted between 2007 and 2019, with a mean follow-up period of 16.4 months (range, 1-60 months). In the included studies, indications for transplant were varied. Common indications were diabetic nephropathy $(n=36,17.9 \%)$, glomerulonephritis $(n=17,8.5 \%)$, and hypertension $(n=13,6.5 \%)$. Other eight indications are listed in Table 3. Bariatric surgeries conducted in the studies were LSG (7 studies), RYGB (6 studies), biliopancreatic diversion and duodenal switch (BPD-DS; 2 studies), laparoscopic adjustable gastric banding (1 study), vertical banded gastroplasty (1 study), and gastric restrictive surgery (GR; 1 study) (Table 1). 


\section{Bariatric surgery before transplant}

In the studies investigating bariatric surgery prior to KTX, the mean age of the patients at the time of surgery was 52.7 years. The weighted mean BMI at baseline was $43.4(5.7) \mathrm{kg} / \mathrm{m}^{2}$; at a weighted mean 29.1 months follow-up, weighted mean BMI was $33.9(6.3) \mathrm{kg} / \mathrm{m}^{2}$, with an absolute percent reduction of $21.9 \%$ after surgery. The 30 -day mortality after bariatric surgery was $0.2 \%(n=1)$. In total, $83 \%\left(95 \%\right.$ CI, 57\%-99\%; 11 studies, $\left.\mathrm{I}^{2}=95 \%\right)$ of patients were successfully listed for KTX after bariatric surgery (Figure 2). Of the 247 patients listed for transplant, 83\% (95\% CI, 65-97\%; 11 studies, $\left.\mathrm{I}^{2}=88 \%\right)$ of these patients successfully received a transplant (Figure 3). The mean time between bariatric surgery to KTX was 24.3 (14.5) months. Deceased donor transplants accounted for $63.7 \%$ of transplanted kidneys. Subgroup analysis by donor type was not possible as included studies did not report the outcomes separately.

The most common baseline comorbidities were T2DM and hypertension (Supplementary Table 1). Overall, there was 56\% (95\% CI, 38\%-74\%) improvement or remission of T2DM after bariatric surgery ( 6 studies, $\mathrm{I}^{2}=62 \%$ ). Improvement or remission of hypertension was noted in $46 \%\left(95 \%\right.$ CI, 33\%-59\%) of the patients (6 studies, $\left.\mathrm{I}^{2}=55 \%\right)$. There was one case of 30 -day mortality; this was due to sleeve staple line leakage on postoperative day $21 .{ }^{35}$ Minor complications within 30-days of bariatric surgery occurred in 7 patients $(1.8 \%)$, and major complications occurring within 30-days happened in 6 patients $(1.6 \%)$. Complications greater than 30-days following bariatric surgery were reported in 10 of the studies; overall, 3 complications occurred $(0.71 \%$ of the patients who underwent bariatric surgery). These complications were mild gastritis, ${ }^{40}$ mild gastroesophageal reflux ${ }^{35}$, and late dumping syndrome. ${ }^{40}$ The 1-year graft survival rate was $98 \%$ (95\% CI, 91\%-100\%; 7 studies, $\mathrm{I}^{2}=55 \%$ ). Graft survival beyond 1-year was included in three studies, and graft survival beyond 1-year was $100 \%$ in these studies.

\section{Bariatric surgery after transplant}

In the studies examining bariatric surgery after KTX, the mean time between KTX and bariatric surgery was 80.4 (38.4) months. At the time of surgery, the weighted mean age was 47.4 years. At baseline, the weighted mean BMI was $43.8(2.2) \mathrm{kg} / \mathrm{m}^{2}$; at an average 19.5 months postbariatric surgery, the weighted mean BMI was $34.2(6.7) \mathrm{kg} / \mathrm{m}^{2}$, with an absolute percent reduction of $21.9 \%$ after surgery. All-cause 30 -day mortality after bariatric surgery was $1.9 \%$ $(n=2)$ across all included studies. Two patients (3.1\%) sustained minor complications within 30days of bariatric surgery (acute renal failure and wound infection) and one patient (1.6\%) sustained a major complication (sleeve stricture requiring balloon dilatation). Complication rates at greater than 30-days post bariatric surgery were included in 6/10 studies; two were reported. Alexander et $\mathrm{al}^{49}$ reported one death at 120 days following bariatric surgery related to cardiac causes, and Schindel et al. reported one death from a bariatric surgery complication, though neither a date nor cause are listed..$^{48}$ For the purposes of this study, it is classified as a 
complication after 30-days. Graft failure was reported by 8/10 studies, with 11 patients out of 186 patients $(5.9 \%)$ experiencing graft rejection or return to dialysis. Living donor transplants accounted for $23.9 \%$ of transplanted kidneys, deceased donor transplants accounted for $55.9 \%$ of transplanted kidneys, and the remainder were reported or unknown. Subgroup analysis by donor type was not possible as studies did not report the outcomes separately.

T2DM and hypertension were the most commonly identified comorbidities (Supplementary Table 1). Patients who received bariatric surgery after KTX had 38.9\% (95\% CI, $15 \%-100 \%$; 5 studies, $\mathrm{I}^{2}=87 \%$ ) remission or improvement of T2DM after surgery. Hypertension improved or resolved in $45.2 \%$ of the patients (95\% CI 19\%-100\%; 4 studies, $\mathrm{I}^{2}=90 \%$ ) bariatric surgery.

\section{Quality assessment of studies}

The mean MINORS score was 9.7 (0.99) for the 14 non-comparative studies and 17.7 (2.12) for the 6 comparative studies, representing fair quality of evidence. ${ }^{33}$ The MINORS result for individual studies are presented in Supplementary Table 2. In summary, 15/20 (75.0\%) studies included a clearly stated aim, 15/20 studies had prospectively collected the data (75.0\%), all had follow-up time periods appropriate to the study $(20 / 20,100 \%)$, and all studies but one included consecutive patients $(19 / 20,95.0 \%)$. Only $12 / 20$ (60.0\%) studies reported adequate endpoints appropriate to the aim of the study. No study had unbiased assessment of the endpoints $(0 / 20$, $0 \%$ ). Loss to follow-up less than 5\% was both reported and achieved in 13/20 studies, reported but greater than 5\% in the 3/18 studies, and loss to follow-up was not reported in 4/20 studies. For comparative studies, all included an adequate control group that received an optimal comparator intervention. 3/6 (50\%) appropriately matched groups for a sufficient number of confounding variables. A single study $(1 / 6,16.7 \%)$, included a prospective calculation of sample size. $^{20}$

\section{Discussion}

The present study showed that bariatric surgery is safe in patients with obesity and kidney failure prior to KTX, and safe in patients with obesity and a past history of KTX (30-day mortality rate after bariatric surgery being $0 \%$ for both groups). Additionally, the study demonstrated that bariatric surgery is effective in producing substantial weight loss that improves candidacy for KTX, as demonstrated by $83 \%$ of post-bariatric surgery patients qualifying for KTX, and $69 \%$ of these patients receiving bariatric surgery ultimately received KTX. This is a marked increase in KTX, considering that the United Network for Organ Sharing listed that only $29.7 \%$ of KTX recipients have any degree of obesity. ${ }^{18}$ Bariatric surgery is also effective in reducing prevalence of common comorbidities likes T2DM, hypertension, and dyslipidemia, and thereby reducing the comorbidity load and optimizing patients before KTX. It therefore appears that bariatric surgery before KTX may increase KTX candidacy and improve outcomes, and that previous KTX should 


\section{Review: Bariatric surgery and kidney transplant}

not be a contraindication to bariatric surgery. Overall, bariatric surgery provides the same substantial weight loss and benefits to KTX candidates and recipients as it does in the non-obese, non-bariatric surgical population.

Obesity actually confers a paradoxical survival benefit in patients receiving dialysis, despite deleterious effects on eventual KTX outcomes. ${ }^{50-53}$ The 'obesity paradox' creates a challenge in managing obese kidney failure patients on dialysis who need to undergo weight reduction prior to being listed for transplant candidacy. The present study demonstrates a benefit of bariatric surgery in reducing wait and improving candidacy for KTX through decreased BMI, with the majority of bariatric surgery recipients being listed for KTX. Thus, bariatric surgery may provide a more expeditious route to weight reduction as well as time to KTX in a population that may otherwise suffer from more longitudinal weight reduction efforts while on dialysis.

Graft survival can be increased beyond solely reducing one's BMI by reducing the prevalence of comorbidities in obese patients with kidney failure. New onset or existing DM persisting into the post-transplant period is strongly associated with poorer post-transplant graft and patient outcomes. ${ }^{54-56}$ The present study found that bariatric surgery is effective in reducing comorbidities in both pre-KTX and post-KTX patients, with $64 \%$ of patients with T2DM before bariatric surgery experiencing improvement or remission of T2DM, and 72\% of patients who received bariatric surgery after KTX experiencing improvement or remission of their T2DM. Hence, bariatric surgery can play an important role in optimizing patients pre-transplant, as well as, decreasing the rate of post-transplant diabetes and subsequent effects on graft function.

Inappropriate weight, including obesity, is responsible for $6 \%$ of the inactive status patients awaiting KTX in the United States; this is the fourth leading cause of inactivation in those previously listed for KTX. ${ }^{57}$ In addition, studies have demonstrated that patients with obesity who qualify for the active status list are less likely to receive a transplant than non-obese counterparts; in fact, the degree of obesity was directly related to likelihood of being overlooked for KTX. ${ }^{58,59}$ This study supports bariatric surgery as a successful tool for increasing access to KTX in the end-stage renal disease patient with obesity and for reducing comorbidity load in the patient post-KTX.

The present study aimed to characterize the effects of bariatric surgery on KTX candidacy through substantial and sustained weight loss, and to assess whether bariatric surgery prior to, or following KTX can improve patient outcomes. Our pooled estimates suggest that bariatric surgery can be performed safely in the pre-KTX and post-KTX patient as a weightreduction intervention and as a tool to reduce comorbidity load. Hence, it may serve as an important intervention in this population to confer a survival benefit and augment graft outcomes and should be appropriately presented to eligible patients. To our knowledge, this is the first systematic review and meta-analysis on the impact of bariatric surgery on KTX outcomes.

The findings in this study should be interpreted in light of the following limitations. First, all studies were observational or non-randomized control studies, leading to a low certainty of 


\section{Review: Bariatric surgery and kidney transplant}

evidence in all outcomes. No randomized controlled trials examining the effect of bariatric surgery on pre-KTX and post-KTX outcomes were found in the literature. Heterogeneity between included studies was high ( $>50 \%$ ) for many outcomes. Although we conducted sensitivity analyses to address this heterogeneity, our present results failed to explain why heterogeneity was present across pooled effect estimates. A source of significant heterogeneity was the wide range of follow-up time points across included studies. This highlights the need to create a standard set of patient-level markers and outcomes with clearly defined time intervals if the effect of bariatric surgery on KTX is to be explored further. In addition, there is a need for comprehensive reporting in the bariatric surgery population with data stratified by type of surgery patients received and indications for surgery, which limited comparisons in this review. Moreover, conducting a subgroup analysis by donor type (e.g. living versus deceased donors) was not possible and this may have impacted the graft failure outcomes post KTX. ${ }^{60}$ Finally, there was no analysis of long-term follow-up for those receiving bariatric surgery pre-KTX to determine if weight loss was sustained in the post-transplant period in the long-term and whether outcomes were impacted. Ultimately, more robust evidence that directly compares KTX outcomes in bariatric surgery and non-bariatric surgery groups are needed before definitive conclusions can be made.

\section{Conclusions}

The present study demonstrates that bariatric surgery is a safe and effective intervention to reduce weight and comorbidities in both the pre-KTX and post-KTX patient. As demonstrated by the heterogeneity of our findings, there is no universally accepted BMI cut-off or time interval relative to KTX to warrant intervention with bariatric surgery in the pre-KTX and post-KTX patients. Research into optimal timing and criteria for bariatric surgery in this population should be considered in future studies. 


\section{Review: Bariatric surgery and kidney transplant}

\section{References}

1. WHO. Obesity and overweight: Fact sheet. WHO Media Cent. Published online 2016.

2. Mendis S, Armstrong T, Bettcher D, et al. Global Status Report on Noncommunicable Diseases 2014. World Health Organisation.; 2014. doi:ISBN 9789241564854

3. Bolignano D, Zoccali C. Effects of weight loss on renal function in obese CKD patients: a systematic review. Nephrol Dial Transplant. 2013;28(suppl_4):iv82-iv98.

4. Viscido G, Gorodner V, Signorini FJ, et al. Sleeve Gastrectomy after Renal Transplantation. Obes Surg. 2018;28(6):1587-1594. doi:10.1007/s11695-017-3056-0

5. Knoll G, Cockfield S, Blydt-Hansen T, et al. Canadian Society of Transplantation consensus guidelines on eligibility for kidney transplantation. Cmaj. 2005;173(10):11811184. doi:10.1503/cmaj.051291

6. Nicoletto BB, Fonseca NKO, Manfro RC, Gonçalves LFS, Leitão CB, Souza GC. Effects of obesity on kidney transplantation outcomes: A systematic review and meta-analysis. Transplantation. 2014;98(2):167-176. doi:10.1097/TP.0000000000000028

7. Lafranca JA, IJermans JNM, Betjes MGH, Dor FJMF. Body mass index and outcome in renal transplant recipients: A systematic review and meta-analysis. BMC Med. Published online 2015. doi:10.1186/s12916-015-0340-5

8. Gore JL, Pham PT, Danovitch GM, et al. Obesity and outcome following renal transplantation. Am J Transplant. 2006;6(2):357-363. doi:10.1111/j.16006143.2005.01198.x

9. Singh D, Lawen J, Alkhudair W. Does pretransplant obesity affect the outcome in kidney transplant recipients? Transplant Proc. 2005;37(2):717-720. doi:10.1016/j.transproceed.2004.12.033

10. Zrim S, Furlong T, Grace BS, Meade A. Body mass index and postoperative complications in kidney transplant recipients. Nephrology. Published online 2012. doi:10.1111/j.1440-1797.2012.01621.x

11. Furriel F, Parada B, Campos L, et al. Pretransplantation overweight and obesity: Does it really affect kidney transplantation outcomes? Transplant Proc. 2011;43(1):95-99. doi:10.1016/j.transproceed.2010.12.027

12. Udgiri NR, Kashyap R, Minz M. The impact of body mass index on renal transplant outcomes: a significant independent risk factor for graft failure and patient death. Transplantation. 2003;75(2):249.

13. Tran M-H, Foster CE, Kalantar-Zadeh K, Hirohito I. Kidney transplantation in obese patients. World J Transplant. 2016;6(2):135-143. doi:10.5500/wjt.v5.i4.287

14. Modanlou KA, Muthyala U, Xiao H, et al. Bariatric surgery among kidney transplant candidates and recipients: Analysis of the united states renal data system and literature review. Transplantation. 2009;87(8):1167-1173. doi:10.1097/TP.0b013e31819e3f14

15. Gazzetta PG, Bissolati M, Saibene A, et al. Bariatric Surgery to Target Obesity in the Renal Transplant Population: Preliminary Experience in a Single Center. Transplant Proc. 2017;49(4):646-649. doi:10.1016/j.transproceed.2017.02.032

16. Abbott KC, Glanton CW, Trespalacios FC, et al. Body mass index, dialysis modality, and survival: Analysis of the United States Renal Data System Dialysis Morbidity and 
Mortality Wave II Study. Kidney Int. 2004;65(2):597-605. doi:10.1111/j.15231755.2004.00385.x

17. Ahmadi SF, Zahmatkesh G, Streja E, et al. Body mass index and mortality in kidney transplant recipients: A systematic review and meta-analysis. Am J Nephrol. 2014;40(4):315-324. doi:10.1159/000367812

18. Cannon RM, Jones CM, Hughes MG, Eng M, Marvin MR. The Impact of Recipient Obesity on Outcomes After Renal Transplantation. Ann Surg. 2013;257(5):978-984. doi:10.1097/SLA.0b013e318275a6cb

19. Cashion AK, Hathaway DK, Stanfill A, et al. Pre-transplant predictors of one yr weight gain after kidney transplantation. Clin Transplant. 2014;28(11):1271-1278. doi:10.1111/ctr.12456

20. Gheith O, Al-Otaibi T, Halim MA, et al. Bariatric surgery in renal transplant patients. Exp Clin Transplant. 2017;15(February 2018):164-169. doi:10.6002/ect.mesot2016.P35

21. Navaneethan SD, Yehnert H, Moustarah F, Schreiber MJ, Schauer PR, Beddhu S. Weight loss interventions in chronic kidney disease: A systematic review and meta-analysis. Clin J Am Soc Nephrol. Published online 2009. doi:10.2215/CJN.02250409

22. Jensen MD, Ryan DH, Apovian CM, et al. 2013 AHA/ACC/TOS guideline for the management of overweight and obesity in adults: A report of the American College of cardiology/American Heart Association task force on practice guidelines and the obesity society. Circulation. 2014;129(25 SUPPL. 1). doi:10.1161/01.cir.0000437739.71477.ee

23. Colquitt JL, Pickett K, Loveman E, Frampton GK. Surgery for weight loss in adults. Cochrane Database Syst Rev. 2014;2014(8). doi:10.1002/14651858.CD003641.pub4

24. Cai R, Wu M, Xing Y. $<$ p $>$ Pretransplant metabolic syndrome and its components predict post-transplantation diabetes mellitus in Chinese patients receiving a first renal transplant. Ther Clin Risk Manag. 2019; Volume 15:497-503. doi:10.2147/tcrm.s190185

25. Wolfe RA, Ashby VB, Milford EL, et al. Comparison of mortality in all patients on dialysis, patients on dialysis awaiting transplantation, and recipients of a first cadaveric transplant. N Engl J Med. Published online 1999. doi:10.1056/NEJM199912023412303

26. Rabbat CG, Thorpe KE, Russell JD, Churchill DN. Comparison of mortality risk for dialysis patients and cadaveric first renal transplant recipients in Ontario, Canada. $J$ Am Soc Nephrol. 2000;11(5):917-922.

27. Meier-Kriesche HU, Ojo AO, Port FK, Arndorfer JA, Cibrik DM, Kaplan B. Survival improvement among patients with end-stage renal disease: Trends over time for transplant recipients and wait-listed patients. J Am Soc Nephrol. 2001;12(6):1293-1296.

28. Oniscu GC, Brown H, Forsythe JLR. Impact of cadaveric renal transplantation on survival in patients listed for transplantation. J Am Soc Nephrol. 2005;16(6):1859-1865. doi:10.1681/ASN.2004121092

29. Port FK, Wolfe RA, Mauger EA, Berling DP, Jiang K. Comparison of Survival Probabilities for Dialysis Patients vs Cadaveric Renal Transplant Recipients. JAMA J Am Med Assoc. Published online 1993. doi:10.1001/jama.1993.03510110079036

30. Snyder JJ, Kasiske BL, Gilbertson DT, Collins AJ. A comparison of transplant outcomes in peritoneal and hemodialysis patients. Kidney Int. 2002;62(4):1423-1430. doi:10.1111/j.1523-1755.2002.kid563.x 
31. Moher D, Liberati A TJ and AD. The PRISMA Group. Preferred Reporting Items for Systematic Reviews and Meta-Analyses: The PRISMA Statement. Ann Intern Med. 2009;151(4):264-269. doi:10.7326/0003-4819-151-4-200908180-00135

32. Dindo D, Demartines N, Clavien P-A. Classification of surgical complications: a new proposal with evaluation in a cohort of 6336 patients and results of a survey. Ann Surg. 2004;240(2):205-213. doi:10.1097/01.SLA.0000133083.54934.AE

33. Slim K, Nini E, Forestier D, Kwiatkowski F, Panis Y, Chipponi J. Methodological index for non-randomized studies (Minors): Development and validation of a new instrument. ANZ J Surg. Published online 2003. doi:10.1046/j.1445-2197.2003.02748.x

34. Bouchard P, Tchervenkov J, Demyttenaere S, Court O, Andalib A. Safety and efficacy of the sleeve gastrectomy as a strategy towards kidney transplantation. Surg Endosc. Published online July 2019. doi:10.1007/s00464-019-07042-z

35. Yemini R, Nesher E, Carmeli I, et al. Bariatric Surgery Is Efficacious and Improves Access to Transplantation for Morbidly Obese Renal Transplant Candidates. Obes Surg. Published online 2019. doi:10.1007/s11695-019-03925-1

36. Cohen JB, Tewksbury CM, Torres Landa S, Williams NN, Dumon KR. National Postoperative Bariatric Surgery Outcomes in Patients with Chronic Kidney Disease and End-Stage Kidney Disease. Obes Surg. 2019;29(3):975-982. doi:10.1007/s11695-0183604-2

37. Thomas IA, Gaynor JJ, Joseph T, et al. Roux-en-Y gastric bypass is an effective bridge to kidney transplantation: Results from a single center. Clin Transplant. 2018;32(5):e13232. doi:10.1111/ctr.13232

38. Newcombe V, Blanch A, Slater GH, Szold A, Fielding GA. Laparoscopic adjustable gastric banding prior to renal transplantation. Obes Surg. 2005;15(4):567-570. doi:10.1381/0960892053723349

39. Kim Y, Bailey AJ, Morris MC, Kassam A-F, Shah SA, Diwan TS. Kidney transplantation after sleeve gastrectomy in the morbidly obese candidate: results of a 2year experience. Surg Obes Relat Dis. 2020;16(1):10-14. doi:10.1016/j.soard.2019.09.069

40. Kienzl-Wagner K, Weissenbacher A, Gehwolf P, Wykypiel H, Öfner D, Schneeberger S. Laparoscopic sleeve gastrectomy: gateway to kidney transplantation. Surg Obes Relat Dis. 2017;13(6):909-915. doi:10.1016/j.soard.2017.01.005

41. Kassam A-F, Mirza A, Kim Y, et al. Long-term outcomes in patients with obesity and renal disease after sleeve gastrectomy. Am J Transplant. 2020;20(2):422-429. doi:10.1111/ajt.15650

42. Koshy AN, Coombes JS, Wilkinson S, Fassett RG. Laparoscopic Gastric Banding Surgery Performed in Obese Dialysis Patients Prior to Kidney Transplantation. Am J Kidney Dis. 2008;52(4):15-17. doi:10.1053/j.ajkd.2008.05.016

43. Al-Bahri S, Fakhry TK, Gonzalvo JP, Murr MM. Bariatric surgery as a bridge to renal transplantation in patients with end-stage renal disease. Obes Surg. 2017;27(11):29512955.

44. Carandina S, Genser L, Bossi M, et al. Laparoscopic Sleeve Gastrectomy in Kidney Transplant Candidates: a Case Series. Obes Surg. 2017;27(10):2613-2618. 


\section{Review: Bariatric surgery and kidney transplant}

doi:10.1007/s11695-017-2679-5

45. Golomb I, Winkler J, Ben-Yakov A, Benitez CC, Keidar A. Laparoscopic sleeve gastrectomy as a weight reduction strategy in obese patients after kidney transplantation. Am J Transplant. 2014;14(10):2384-2390. doi:10.1111/ajt.12829

46. Arias RH, Mesa L, Posada JG, Vélez JP. Kidney transplantation and gastric bypass: A better control of comorbidities. Obes Surg. 2010;20(7):851-854. doi:10.1007/s11695010-0165-4

47. Szomstein S, Rojas R, Rosenthal RJ. Outcomes of laparoscopic bariatric surgery after renal transplant. Obes Surg. 2010;20(3):383-385. doi:10.1007/s11695-009-9969-5

48. Schindel H, Winkler J, Yemini R, Carmeli I, Nesher E, Keidar A. Survival benefit in bariatric surgery kidney recipients may be mediated through effects on kidney graft function and improvement of co-morbidities: A case-control study. Surg Obes Relat Dis. 2019;15(4):621-627. doi:10.1016/j.soard.2019.01.034

49. Alexander JW, Goodman H. Gastric bypass in chronic renal failure and renal transplant. Nutr Clin Pract. 2007;22(1):16-21. doi:10.1177/011542650702200116

50. Navaneethan SD, Schold JD, Srinivas TR. Metabolic Syndrome and Mild to Moderate Chronic Kidney Disease Among Minorities. Semin Nephrol. Published online 2010. doi:10.1016/j.semnephrol.2009.10.008

51. Armstrong KA, Campbell SB, Hawley CM, Nicol DL, Johnson DW, Isbel NM. Obesity is associated with worsening cardiovascular risk factor profiles and proteinuria progression in renal transplant recipients. Am J Transplant. 2005;5(11):2710-2718. doi:10.1111/j.1600-6143.2005.01073.x

52. Kramer HJ, Saranathan A, Luke A, et al. Increasing body mass index and obesity in the incident ESRD population. J Am Soc Nephrol. 2006;17(5):1453-1459.

53. Lassalle M, Fezeu LK, Couchoud C, Hannedouche T, Massy ZA, Czernichow S. Obesity and access to kidney transplantation in patients starting dialysis: A prospective cohort study. PLoS One. Published online 2017. doi:10.1371/journal.pone.0176616

54. Vesco L, Busson M, Bedrossian J, Bitker MO, Hiese C, Lang P. DIABETES MELLITUS AFTER RENAL TRANSPLANTATION : Characteristics, Outcome, and Risk Factors. Transplantation. 1996;61(10):1475-1478.

55. Kasiske BL, Snyder JJ, Gilbertson D, Matas AJ. Diabetes Mellitus after Kidney Transplantation in the United States Bertram. Am J Transplant. 2003;3(10):178-185. doi:10.1046/j.1600-6143.2003.00228.x

56. Cosio FG, Kudva Y, Van Der Velde M, et al. New onset hyperglycemia and diabetes are associated with increased cardiovascular risk after kidney transplantation. Kidney Int. 2005;67(6):2415-2421. doi:10.1111/j.1523-1755.2005.00349.x

57. Matas A, Smith J, Skeans M, et al. OPTN/SRTR 2012 Annual Data Report: Kidney. Am J Transplant. 2014;14(SUPPL. 1):11-44. doi:http://dx.doi.org/10.1111/ajt.12579

58. Segev DL, Simpkins CE, Thompson RE, Locke JE, Warren DS, Montgomery RA. Obesity impacts access to kidney transplantation. J Am Soc Nephrol. 2008;19(2):349355. doi:10.1681/ASN.2007050610

59. Gill JS, Hendren E, Dong J, Johnston O, Gill J. Differential association of body mass index with access to kidney transplantation in men and women. Clin J Am Soc Nephrol. 
2014;9(5):951-959. doi:10.2215/CJN.08310813

60. Foroutan F, Friesen EL, Clark KE, et al. Risk factors for 1-year graft loss after kidney transplantation systematic review and meta-analysis. Clin J Am Soc Nephrol. 2019;14(11):1642-1650. doi:10.2215/CJN.05560519

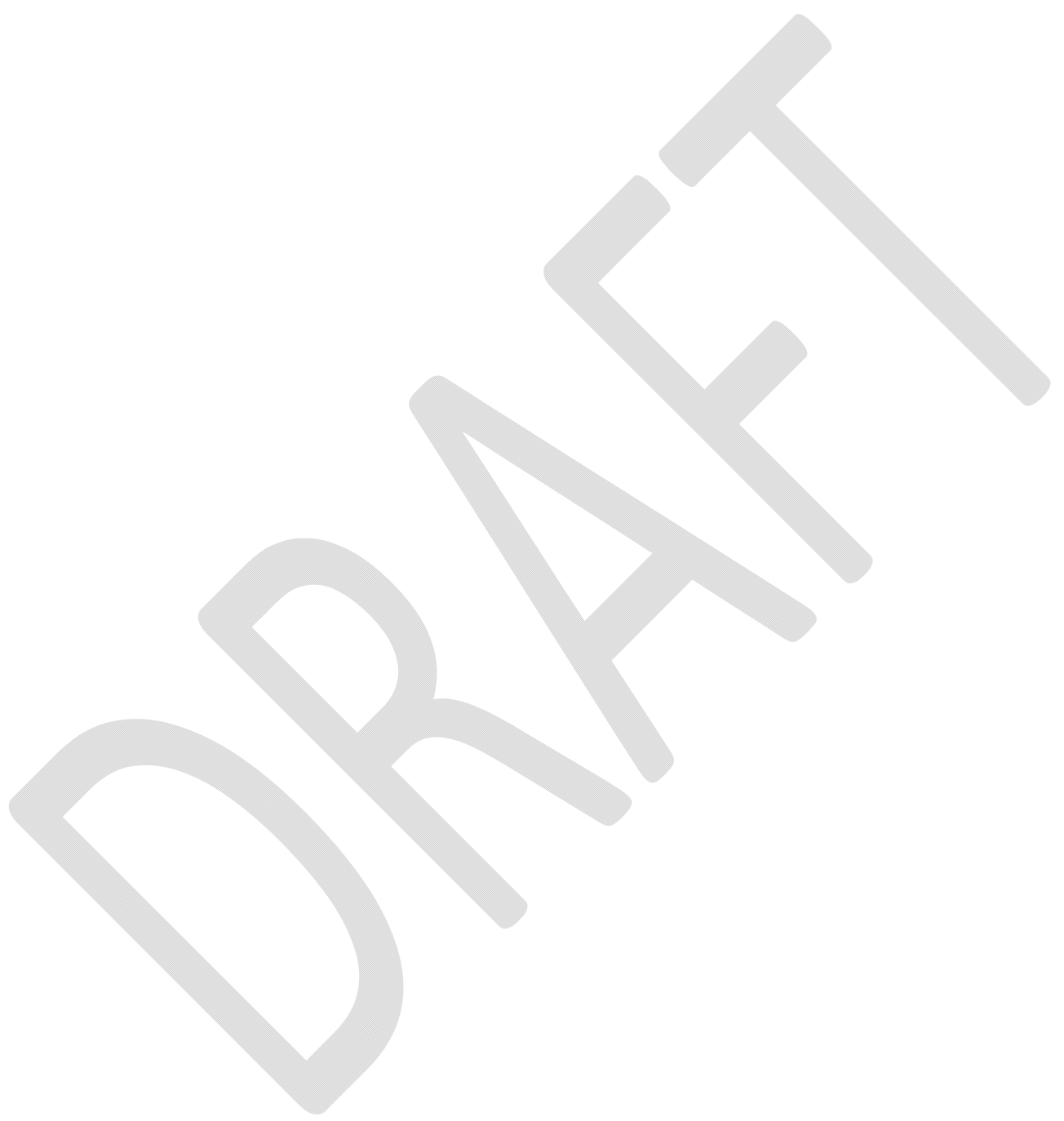




\section{Tables and Figures}

Fig. 1. PRISMA flow diagram.

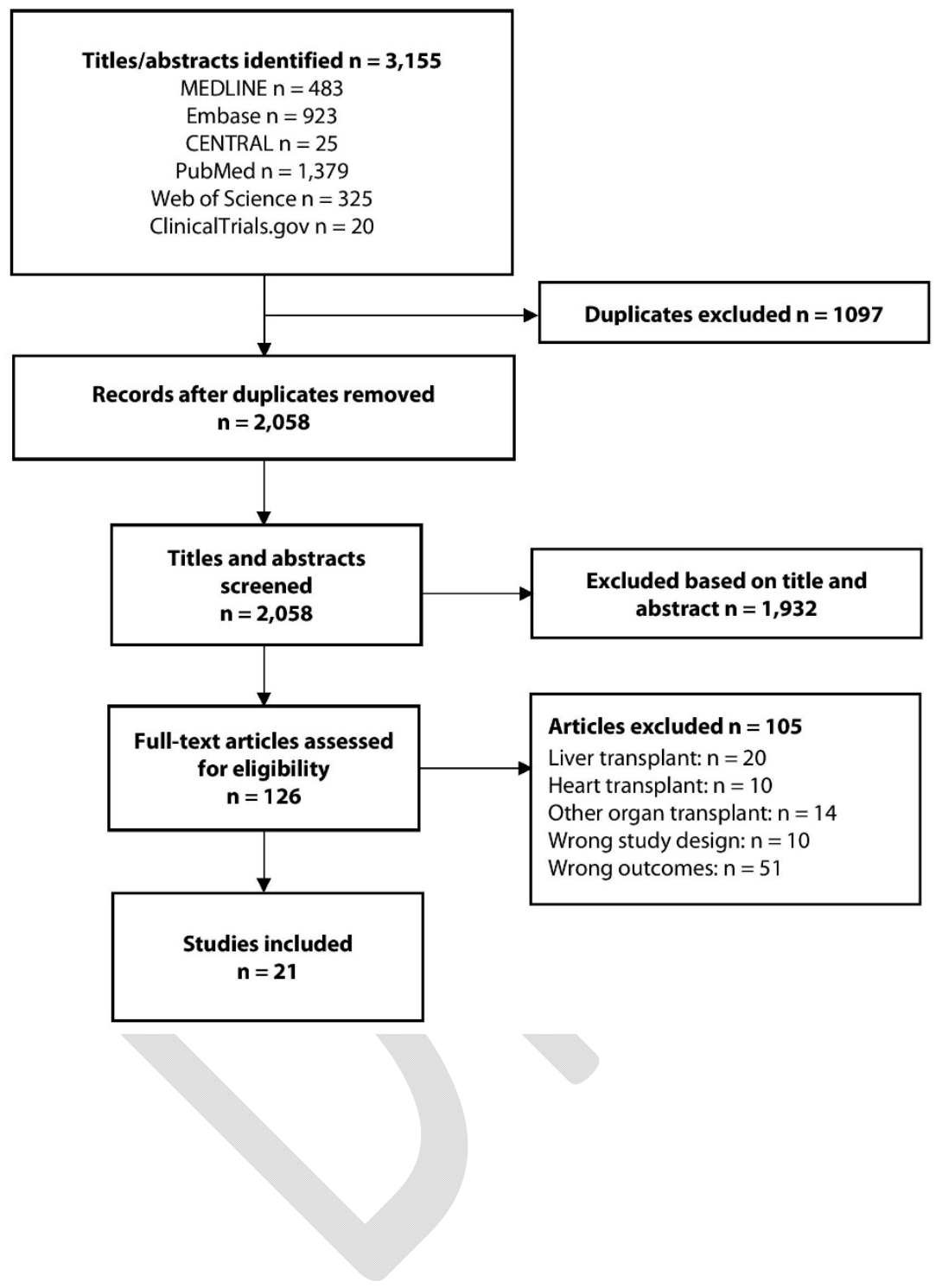


Fig. 2. Patients listed for kidney transplant.

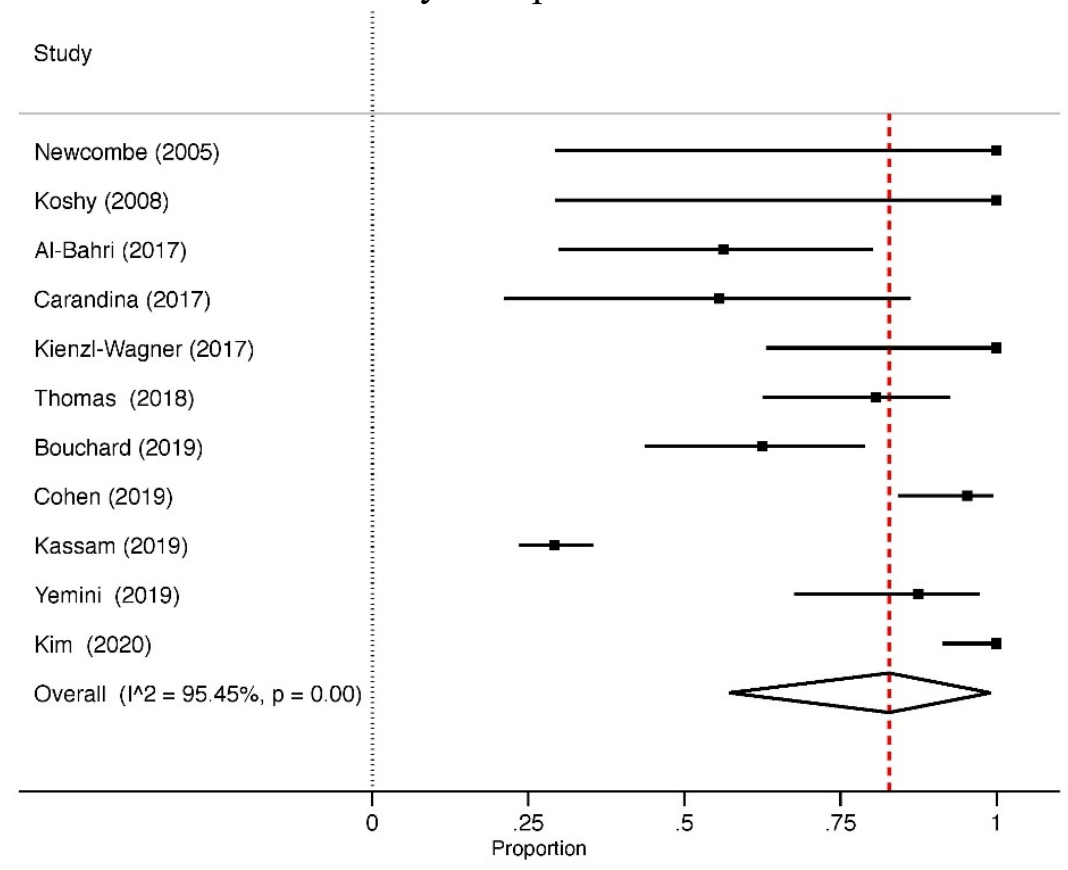

Fig. 3. Patients with successful kidney transplant.

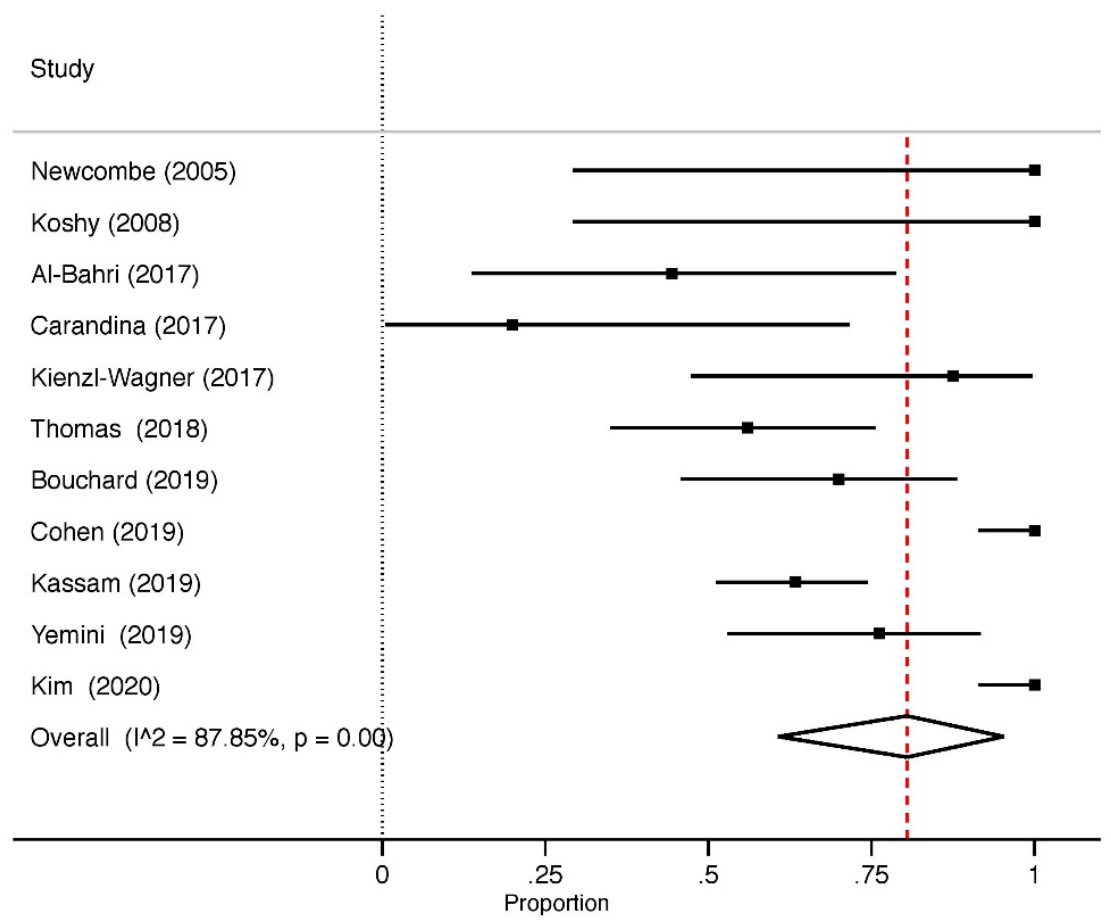


Table 1. Characteristics of studies with patients that underwent bariatric surgery before and after kidney transplantation

\begin{tabular}{|c|c|c|c|c|c|c|c|c|c|c|}
\hline Study & Country & Study sesign & $\begin{array}{l}\text { Type of } \\
\text { bariatric } \\
\text { surgery }\end{array}$ & $\mathbf{n}$ & $\% \mathbf{F}$ & $\begin{array}{l}\text { Age } \\
\text { (SD) }\end{array}$ & $\begin{array}{l}\text { FU } \\
\text { (mo, } \\
\text { SD) }\end{array}$ & $\begin{array}{l}\text { Pre- } \\
\text { bariatric } \\
\text { Sx BMI, } \\
\mathrm{kg} / \mathbf{m}^{2} \\
\text { (SD) }\end{array}$ & $\begin{array}{l}\text { Post- } \\
\text { bariatric Sx } \\
\text { BMI, kg/m }{ }^{2} \\
\text { (SD) }\end{array}$ & $\begin{array}{l}\% \\
\text { EWL } \\
\text { (SD) }\end{array}$ \\
\hline \multicolumn{11}{|c|}{ Before kidney transplant } \\
\hline $\begin{array}{l}\text { Bouchard, } \\
2019\end{array}$ & Canada & $\begin{array}{l}\text { Retrospective } \\
\text { cohort }\end{array}$ & LSG & 32 & 44 & $\begin{array}{c}51 \\
(11)\end{array}$ & 14 & $42.3(5.2)$ & $31(9)$ & $\begin{array}{l}56 \\
(27)\end{array}$ \\
\hline Yemini, 2019 & Israel & $\begin{array}{l}\text { Retrospective } \\
\text { cohort }\end{array}$ & $\begin{array}{c}\text { LSG, n=17 } \\
\text { RYGB, } \\
n=7\end{array}$ & 24 & 33 & $\begin{array}{c}54 \\
(3.1)\end{array}$ & $\begin{array}{c}47 \\
(6.5)\end{array}$ & $\begin{array}{c}41.5 \\
(0.79)\end{array}$ & $29(1.3)$ & $\begin{array}{c}66 \\
(6.3)\end{array}$ \\
\hline Cohen, 2019 & U.S. & $\begin{array}{l}\text { Retrospective } \\
\text { cohort }\end{array}$ & $\begin{array}{c}\text { RYGB, } \\
n=27 \\
\text { SG, n=9 } \\
\text { LAGB, n=6 } \\
\text { Unknown, } \\
n=1\end{array}$ & 43 & 41 & 50 & 60 & 43 & 36 & 69 \\
\hline $\begin{array}{l}\text { Thomas, } \\
2018\end{array}$ & U.S. & $\begin{array}{l}\text { Retrospective } \\
\text { cohort }\end{array}$ & RYGB & 31 & 54.8 & $\begin{array}{c}45 \\
(2.2)\end{array}$ & - & $43.5(0.7)$ & 28.1 & $\begin{array}{l}72.8 \\
(3)\end{array}$ \\
\hline Kim, 2020 & U.S. & $\begin{array}{l}\text { Retrospective } \\
\text { cohort }\end{array}$ & LSG & 41 & 46.3 & $\begin{array}{c}56 \\
(9.3)\end{array}$ & $\begin{array}{c}22.2 \\
(16.4)\end{array}$ & $41.1(4.6)$ & $32.1(4.7)$ & - \\
\hline $\begin{array}{l}\text { Newcombe, } \\
2005\end{array}$ & Australia & Case series & LAGB & 3 & 0 & 44 & $\begin{array}{l}16.3 \\
(8.3)\end{array}$ & 44.6 & $33.7(4.95)$ & - \\
\hline
\end{tabular}


Review: Bariatric surgery and kidney transplant

\begin{tabular}{|c|c|c|c|c|c|c|c|c|c|c|}
\hline Koshy, 2008 & U.S. & Case series & LAGB & 3 & 33 & 41 & $\begin{array}{c}13.6 \\
(1.24)\end{array}$ & 40.1 & $34.1(2.76)$ & 37 \\
\hline $\begin{array}{l}\text { Kassam, } \\
2019\end{array}$ & U.S. & $\begin{array}{l}\text { Retrospective } \\
\text { cohort }\end{array}$ & LSG & 243 & 58 & $\begin{array}{c}54 \\
(11.1)\end{array}$ & $\begin{array}{c}28.3 \\
(18.3)\end{array}$ & $44(6.3)$ & $36.7(6.6)$ & $\begin{array}{c}38.2 \\
(20.3)\end{array}$ \\
\hline $\begin{array}{l}\text { Al-Bahri, } \\
2017\end{array}$ & U.S. & Case series & $\begin{array}{c}\text { LSG, } \mathrm{n}=1 \\
\text { RYGB, } \\
\mathrm{n}=12, \\
\text { LAGB, } \mathrm{n}=3\end{array}$ & 16 & 62.5 & $55(7)$ & $48(36)$ & $48(8)$ & $31.7(7)$ & $\begin{array}{c}62 \\
(24)\end{array}$ \\
\hline $\begin{array}{l}\text { Kienzl- } \\
\text { Wagner, } \\
2017\end{array}$ & Austria & Case series & LSG & 8 & 62 & 48 & $\begin{array}{c}38.4 \\
(16.8)\end{array}$ & $38(3.8)$ & $\begin{array}{c}1 \mathrm{yr}=30.4 \\
(10.7) \\
2 \mathrm{yr}=30.7 \\
(4.4) \\
3 \mathrm{yr}=30.7 \\
(6.0)\end{array}$ & - \\
\hline $\begin{array}{l}\text { Carandina, } \\
2017\end{array}$ & France & Case series & LSG & 9 & 88.9 & 53.2 & 15.6 & 45.9 & $\begin{array}{c}6 \mathrm{mo}=36.2 \\
18 \mathrm{mo}=28.3\end{array}$ & 73.2 \\
\hline \multicolumn{11}{|c|}{ After kidney transplant } \\
\hline Cohen, 2019 & U.S. & $\begin{array}{l}\text { Retrospective } \\
\text { cohort }\end{array}$ & $\begin{array}{c}\text { RYGB, } \\
n=6 \\
\text { SG, } n=10 \\
\text { LAGB, } n=4 \\
\text { VBG, } n=1\end{array}$ & 21 & 70 & 41 & 60 & 41 & 32 & 71 \\
\hline $\begin{array}{l}\text { Viscido, } \\
2018\end{array}$ & Argentina & Case series & $\mathrm{SG}$ & 5 & 80 & - & $\begin{array}{c}16.8 \\
(14.5)\end{array}$ & $\begin{array}{c}42.18 \\
(6.8)\end{array}$ & $29.8(7.3)$ & $\begin{array}{c}58.0 \\
(11.8)\end{array}$ \\
\hline $\begin{array}{l}\text { Schindel, } \\
2019\end{array}$ & Israel & Case-sontrol & $\begin{array}{c}\mathrm{LSG}, \mathrm{n}=19 \\
\mathrm{RYGB}, \\
\mathrm{n}=10\end{array}$ & 30 & 36.7 & $\begin{array}{c}55.7 \\
(10.7)\end{array}$ & $\begin{array}{c}7.2 \\
(3.7)\end{array}$ & $41.3(3.7)$ & $29.5(4.7)$ & $\begin{array}{c}71.6 \\
(28.7)\end{array}$ \\
\hline
\end{tabular}




\section{Review: Bariatric surgery and kidney transplant}

\begin{tabular}{|c|c|c|c|c|c|c|c|c|c|c|}
\hline & & & $\begin{array}{c}\text { BPD-DS, } \\
n=1\end{array}$ & & & & & & & \\
\hline \multirow[t]{4}{*}{$\begin{array}{l}\text { Gazzetta, } \\
2017\end{array}$} & \multirow[t]{4}{*}{ Italy } & \multirow[t]{4}{*}{ Case series } & \multirow[t]{4}{*}{ LSG } & \multirow[t]{4}{*}{6} & \multirow[t]{4}{*}{33.3} & \multirow[t]{4}{*}{$\begin{array}{c}50.3 \\
(8.07)\end{array}$} & 1 & $\begin{array}{c}39.8 \\
(5.29)\end{array}$ & - & 27.6 \\
\hline & & & & & & & 3 & - & - & 44.1 \\
\hline & & & & & & & 6 & - & - & 74.2 \\
\hline & & & & & & & 12 & - & - & 75.9 \\
\hline Gheith, 2017 & Kuwait & $\begin{array}{l}\text { Prospective } \\
\text { cohort study }\end{array}$ & - & 22 & 36.4 & $\begin{array}{c}40.6 \\
(12.3)\end{array}$ & 6 & $38.5(9.1)$ & $34.3(7.6)$ & - \\
\hline \multirow[t]{3}{*}{$\begin{array}{l}\text { Golomb, } \\
2014\end{array}$} & \multirow[t]{3}{*}{ Israel } & \multirow[t]{3}{*}{ Case series } & \multirow[t]{3}{*}{ LSG } & \multirow[t]{3}{*}{10} & \multirow[t]{3}{*}{40} & \multirow[t]{3}{*}{$\begin{array}{l}55.3 \\
(7.3)\end{array}$} & 3 & $\begin{array}{c}41.6(596- \\
152)\end{array}$ & 33.0 & - \\
\hline & & & & & & & 6 & - & $\begin{array}{c}31.2(29.1- \\
46.8) \\
\end{array}$ & 57.0 \\
\hline & & & & & & & 12 & - & $\begin{array}{c}29.1(28.1- \\
48.4)\end{array}$ & 75.5 \\
\hline $\begin{array}{l}\text { Szomstein, } \\
2010\end{array}$ & U.S. & Case series & $\begin{array}{c}\text { LSG, } \mathrm{n}=1 \\
\mathrm{RYGB} \\
\mathrm{n}=4\end{array}$ & 5 & 100 & $\begin{array}{c}39 \\
(7.5)\end{array}$ & $\begin{array}{c}23 \\
(2.53)\end{array}$ & $\begin{array}{c}52.2 \\
(9.47)\end{array}$ & $32.2(2.99)$ & $>50$ \\
\hline Arias, 2010 & Colombia & Case series & RYGB & 5 & 40 & $\begin{array}{c}55.2 \\
(10.6)\end{array}$ & $\begin{array}{c}26.4 \\
(1.17)\end{array}$ & $\begin{array}{c}40.2 \\
(1.47)\end{array}$ & $29.2(2.71)$ & - \\
\hline $\begin{array}{l}\text { Alexander, } \\
2007\end{array}$ & U.S. & Case series & RYGB & 10 & - & 44 & 12 & $47.3(6.8)$ & $32.3(5.5)$ & - \\
\hline $\begin{array}{l}\text { Modanlou, } \\
2009\end{array}$ & U.S. & $\begin{array}{l}\text { Retrospective } \\
\text { cohort }\end{array}$ & $\begin{array}{c}\text { RYGB SL, } \\
n=50 \\
\text { RYGB } \\
\text { SIR, } n=20 \\
\text { VSG, } n=10 \\
\text { GR, } n=6\end{array}$ & 87 & 59.8 & $\begin{array}{c}45.2 \\
(11.3)\end{array}$ & 12 & $46.6(4.6)$ & $40.2(7.8)$ & $\begin{array}{l}30.8 \\
(8.7- \\
48.3)\end{array}$ \\
\hline
\end{tabular}




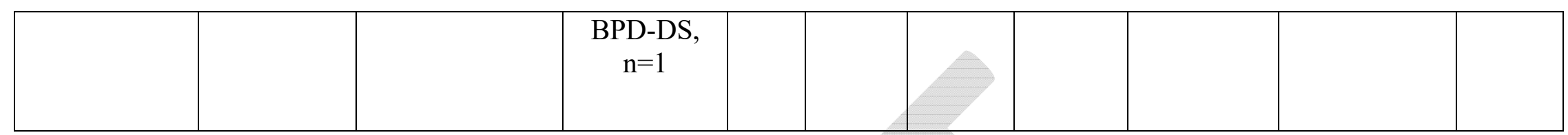

BMI: body mass index; BPD-DS: biliopancreatic diversion with duodenal switch; ESRD: end-stage renal disease; F: female; FU: followup; GR: gastric restrictive; KTX: kidney transplant; LAGB: laparoscopic adjustable gastric band; LSG: laparoscopic sleeve gastrectomy; NIH: National Institute of Health; RYGB: Roux-en-Y gastric bypass; SD: standard deviation; SIR: small intestine reconstruction; SL: short limb; VBG: vertical banded gastroplasty.

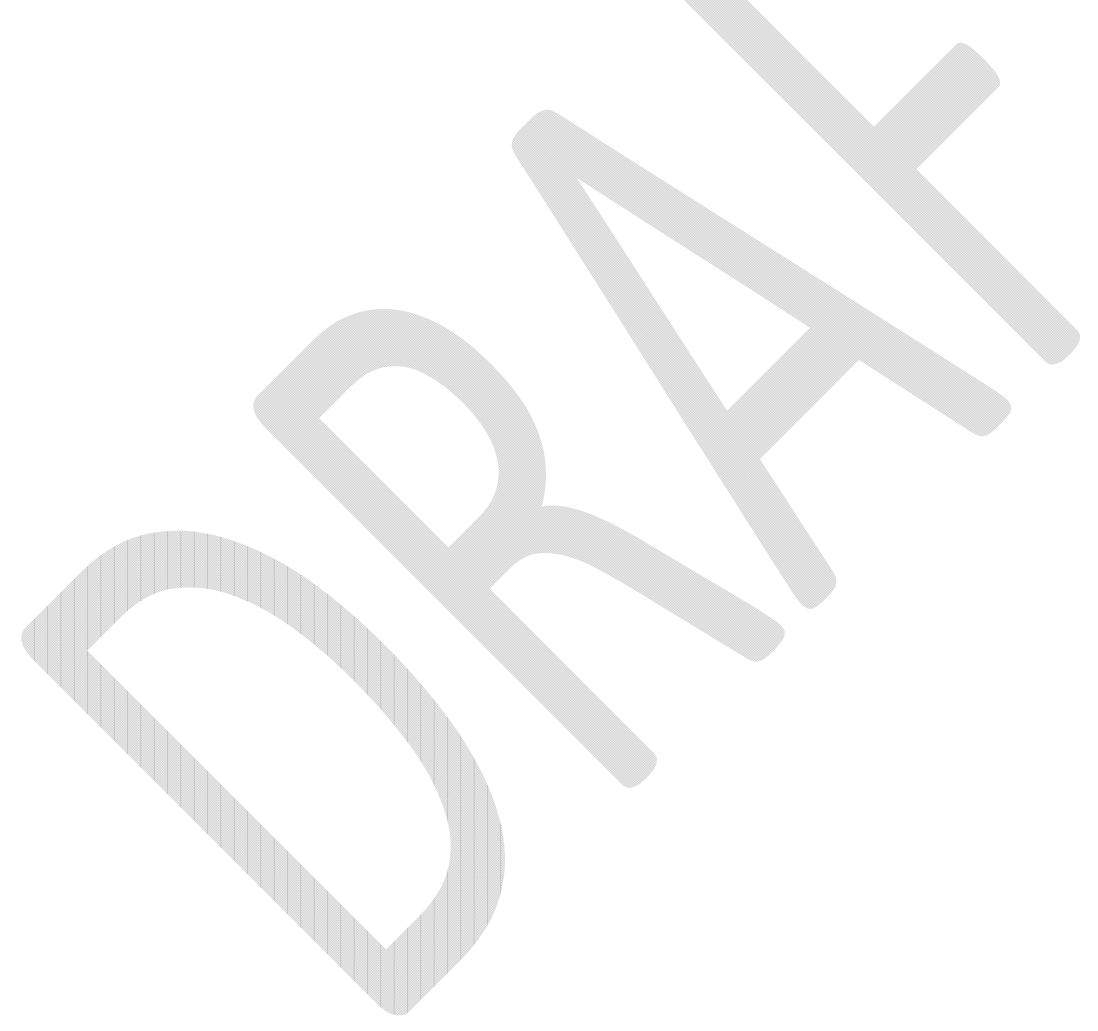


Table 2. Transplant indications and outcomes of patients that underwent bariatric surgery before kidney transplantation

\begin{tabular}{|c|c|c|c|c|c|c|c|c|}
\hline Author & n & $\begin{array}{l}\text { Kidney transplant } \\
\text { indications }\end{array}$ & $\begin{array}{l}\text { Type of } \\
\text { donor } \\
\text { kidney }\end{array}$ & $\begin{array}{l}\text { Successfully } \\
\text { listed for } \\
\text { transplant, } \\
\text { n }(\%)\end{array}$ & $\begin{array}{c}\text { Successfully } \\
\text { received transplant, } \\
\text { n }(\%)\end{array}$ & $\begin{array}{c}\text { Time } \\
\text { from Bari } \\
\text { Sx to } \\
\text { KTX in } \\
\text { Mo (SD) }\end{array}$ & $\begin{array}{l}\text { Graft survival } \\
1 \text { year after } \\
\text { transplant, } \mathbf{n} \\
(\%)\end{array}$ & $\begin{array}{c}\text { Graft survival } \\
5 \text { years after } \\
\text { transplant, } n \\
(\%)\end{array}$ \\
\hline $\begin{array}{l}\text { Bouchard, } \\
2019\end{array}$ & 32 & - & - & $20(63 \%)$ & $14(44 \%)$ & $8(12)$ & $14(100 \%)$ & $14(100 \%)$ \\
\hline Yemini, 2019 & 24 & $\begin{array}{c}\text { DM: } 15 \\
\text { FSGS: } 2 \\
\text { PCKD: } 3 \\
\text { HUS: } 1 \\
\text { Unknown: } 3\end{array}$ & $\begin{array}{l}\text { DD: } 5 \\
(31.2 \%) \\
\text { LD: } 11 \\
(68.8 \%)\end{array}$ & $21(87.5 \%)$ & $16(76.2 \%)$ & 18 & $16(100 \%)$ & $16(100 \%)$ \\
\hline Cohen, 2019 & 43 & $\begin{array}{c}\text { DM: } 10(23 \%) \\
\text { HTN: } 5(12 \%) \\
\text { Cystic disease: } 5 \\
\quad(12 \%) \\
\text { Glomerular } \\
\text { Disease: } 2(5 \%) \\
\text { Other: } 21(48 \%)\end{array}$ & $\begin{array}{l}\text { DD: } 25 \\
(61.0 \%) \\
\text { LD: } 16 \\
(39.0 \%)\end{array}$ & $41(95.3 \%)$ & $41(100 \%)$ & 72 & $41(100 \%)$ & - \\
\hline $\begin{array}{l}\text { Thomas, } \\
2018\end{array}$ & 31 & $\begin{array}{l}\text { DM: } 7(50.0 \%) \\
\text { HTN: } 3(21.4 \%) \\
\text { Other: } 4(28.6 \%)\end{array}$ & $\begin{array}{l}\text { DD: } 13 \\
(92.9 \%) \\
\text { LD: } 1 \\
(7.1 \%)\end{array}$ & $25(80.6 \%)$ & $14(45.2 \%)$ & 33 & $10(71.4 \%)$ & - \\
\hline Kim, 2020 & 41 & $\begin{array}{c}\text { DM: } 22(53 \%) \\
\text { HTN: } 11(27 \%) \\
\text { PCKD: } 3(7.3 \%) \\
\text { Other: } 5(12 \%) \\
\end{array}$ & $\begin{array}{l}\text { DD: } 25 \\
(61 \%) \\
\text { LD: } 16 \\
(39 \%) \\
\end{array}$ & $41(100 \%)$ & $41(100 \%)$ & $21.3(16.4)$ & $40(97.6 \%)$ & - \\
\hline
\end{tabular}


Review: Bariatric surgery and kidney transplant

\begin{tabular}{|c|c|c|c|c|c|c|c|c|}
\hline $\begin{array}{l}\text { Newcombe, } \\
2005\end{array}$ & 3 & - & - & $3(100 \%)$ & $3(100 \%)$ & 16 & - & - \\
\hline Koshy, 2008 & 3 & $\begin{array}{c}\text { DM: } 2(66.7 \%) \\
\text { FSGS: } 1(3.33 \%)\end{array}$ & $\begin{array}{l}\text { DD: } 1 \\
(33 \%) \\
\text { LD: } 2 \\
(66 \%)\end{array}$ & $3(100 \%)$ & $3(100 \%)$ & 13.5 & - & - \\
\hline $\begin{array}{l}\text { Kassam, } \\
2019\end{array}$ & 243 & - & $\begin{array}{c}\text { DD: } 30 \\
(66.7 \%) \\
\text { LD: } 15 \\
(33.3 \%)\end{array}$ & $71(29.2 \%)$ & $45(63.4 \%)$ & $22.8(15.6)$ & - & - \\
\hline $\begin{array}{l}\text { Al-Bahri, } \\
2017\end{array}$ & 16 & $\begin{array}{c}\text { FSGS: } 1(25 \%) \\
\text { IgA nephropathy: } 1 \\
(25 \%) \\
\text { DM: } 1(25 \%) \\
\text { HTN: } 1(25 \%)\end{array}$ & $\begin{array}{l}\text { DD: } 3 \\
(75 \%) \\
\text { LD: } 1 \\
(25 \%)\end{array}$ & $9(56.3 \%)$ & $4(25 \%)$ & $25(14)$ & $4(100 \%)$ & - \\
\hline $\begin{array}{l}\text { Kienzl- } \\
\text { Wagner, } \\
2017\end{array}$ & 8 & $\begin{array}{c}\text { DM: } 3(37.5 \%) \\
\text { IgA nephropathy: } 1 \\
(12.5 \%) \\
\text { Analgesic } \\
\text { Nephropathy: } 1 \\
(12.5 \%) \\
\text { Glomerulonephritis: } \\
1(12.5 \%) \\
\text { Reflux Nephritis: } 1 \\
(12.5 \%) \\
\text { Nephropathy: } 1 \\
(12.5 \%) \\
\text { Preeclampsia: } 1 \\
(12.5 \%)\end{array}$ & $\begin{array}{l}\text { DD: } 7 \\
(100 \%)\end{array}$ & $8(100 \%)$ & $(87.5 \%)$ & 17 & $6(87.5 \%)$ & - \\
\hline
\end{tabular}




\begin{tabular}{|l|l|l|l|l|l|l|l|l|}
\hline $\begin{array}{l}\text { Carandina, } \\
2017\end{array}$ & 9 & $\begin{array}{l}\text { DM: } 5(55.6 \%) \\
\text { HTN: } 3(33.3 \%) \\
\text { FSGS: } 1(11.1 \%)\end{array}$ & - & $5(55.5 \%)$ & $1(11.1 \%)$ & 21 & - \\
\hline
\end{tabular}

ATN: acute tubular necrosis; DD: deceased donor; DM: diabetes mellitus; DNR: date not reported; FSGS: focal segmental glomerulosclerosis; HTN: hypertension; HUS: hemolytic uremic syndrome; KTX: kidney transplant; LAGB: laparoscopic adjustable gastric band; LD: living donor; LSG: laparoscopic sleeve gastrectomy; PCKD: polycystic kidney disease; RPGN: rapidly progressive glomerulonephritis; RYGB: Roux-en-Y gastric bypass; SD: standard deviation. 


\begin{tabular}{|c|c|c|c|c|c|}
\hline Author & n & Kidney transplant indications & $\begin{array}{l}\text { Type of kidney } \\
\text { transplant }\end{array}$ & $\begin{array}{c}\text { Time from KTX to } \\
\text { bariatric surgery, } \\
\text { years (SD) }\end{array}$ & $\begin{array}{c}\text { Graft failure or return } \\
\text { to dialysis/rejection } \\
\text { after bariatric surgery } \\
(\mathrm{n}, \%)\end{array}$ \\
\hline $\begin{array}{l}\text { Cohen, } \\
2019\end{array}$ & 21 & $\begin{array}{c}\text { DM, } n=6(28.6 \%) \\
\text { HTN, } n=4(19.0 \%) \\
\text { Glomerular disease, } n=4(19.0 \%) \\
\text { Other, } n=7(33.3 \%)\end{array}$ & $\begin{array}{l}\mathrm{DD}, \mathrm{n}=14(66.7 \%) \\
\mathrm{LD}, \mathrm{n}=7(33.3 \%)\end{array}$ & 5 & $7(33 \%)$ \\
\hline $\begin{array}{l}\text { Viscido, } \\
2018\end{array}$ & 5 & $\begin{array}{c}\text { T1DM, } n=1(20.0 \%) \\
\text { HTN, } n=2(40.0 \%) \\
\text { Congenital defects, } n=1(20.0 \%) \\
\text { SLE, } n=1(20.0 \%) \\
\text { Glomerulonephritis, } n=1(20.0 \%)\end{array}$ & $\begin{array}{c}\text { Unknown, } n=5 \\
(100 \%)\end{array}$ & $15(4.8)$ & - \\
\hline $\begin{array}{l}\text { Schindel, } \\
2019\end{array}$ & 30 & $\begin{array}{c}\text { T2DM, } \mathrm{n}=8(26.7 \%) \\
\text { HTN, } \mathrm{n}=1(3.3 \%) \\
\text { T2DM }+ \text { HTN, } \mathrm{n}=4(13.3 \%) \\
\text { Glomerulonephritis, } \mathrm{n}=4(13.3 \%) \\
\text { Pyruvate kinase deficiency, } \mathrm{n}=1 \\
(3.3 \%) \\
\text { Other, } \mathrm{n}=12(40 \%)\end{array}$ & $\begin{array}{l}\mathrm{LD}, \mathrm{n}=16(53.3 \%) \\
\text { Unknown, } \mathrm{n}=14 \\
(46.7 \%)\end{array}$ & $4.6(3.1)$ & $1(3.3 \%)$ \\
\hline $\begin{array}{l}\text { Gazzetta, } \\
2017\end{array}$ & 6 & $\begin{array}{c}\text { T2DM, } \mathrm{n}=3(50.0 \%) \\
\text { IgA nephritis, } \mathrm{n}=1(16.7 \%) \\
\text { Idiopathic, } \mathrm{n}=1(16.7 \%) \\
\text { Obstructive congenital disorder, } \\
\mathrm{n}=1(16.7 \%)\end{array}$ & $\begin{array}{c}\text { Unknown, } \mathrm{n}=6 \\
(100 \%)\end{array}$ & 7.6 & $0(0 \%)$ \\
\hline $\begin{array}{l}\text { Gheith, } \\
2017\end{array}$ & 22 & $\begin{array}{c}\text { Glomerulonephritis, } \mathrm{n}=8(36.4 \%) \\
\mathrm{DM}, \mathrm{n}=5(22.7 \%)\end{array}$ & $\begin{array}{c}\text { Living related, } \mathrm{n}=6 \\
(27.2 \%)\end{array}$ & - & $1(4.5 \%)$ \\
\hline
\end{tabular}




\begin{tabular}{|c|c|c|c|c|c|}
\hline & & $\begin{array}{l}\text { HTN, } n=1(4.5 \%) \\
\text { Other, } n=8(36.4 \%)\end{array}$ & $\begin{array}{l}\text { Living unrelated, } \\
\mathrm{n}=12(54.5 \%) \\
\mathrm{DD}, \mathrm{n}=4(18.2 \%)\end{array}$ & & \\
\hline $\begin{array}{l}\text { Golomb, } \\
2014\end{array}$ & 10 & $\begin{array}{c}\text { IgA nephropathy, } \mathrm{n}=1(10.0 \%) \\
\text { DM, } \mathrm{n}=4(40.0 \%) \\
\text { Chronic interstitial nephritis, } \mathrm{n}=1 \\
(10.0 \%) \\
\text { Glomerulonephritis, } \mathrm{n}=1(10.0 \%) \\
\text { Dicophenac sodium overdose, } \\
\mathrm{n}=1(10.0 \%) \\
\text { DM + HTN, } \mathrm{n}=1(10.0 \%) \\
\text { Unknown, } \mathrm{n}=1(10.0 \%)\end{array}$ & $\begin{array}{l}\mathrm{DD}, \mathrm{n}=4(40 \%) \\
\mathrm{LD}, \mathrm{n}=6(60 \%)\end{array}$ & $5.27(2.26)$ & $0(0 \%)$ \\
\hline $\begin{array}{l}\text { Szomstein, } \\
2010\end{array}$ & 5 & $\begin{array}{c}\text { PCKD, } \mathrm{n}=1(20.0 \%) \\
\text { DM, } \mathrm{n}=2(40.0 \%) \\
\text { Glomerulonephritis, } \mathrm{n}=1(20.0 \%) \\
\text { CKD, } \mathrm{n}=1(20.0 \%)\end{array}$ & $\begin{array}{c}\text { DD, } n=1(20 \%) \\
\text { LD, } n=1(20 \%) \\
\text { Unknown, } n=3 \\
(60 \%)\end{array}$ & - & $0(0 \%)$ \\
\hline Arias, 2010 & 5 & $\begin{array}{c}\mathrm{DM}, \mathrm{n}=2(40.0 \%) \\
\text { Glomerulonephritis, } \mathrm{n}=2(40.0 \%) \\
\text { Unknown, } \mathrm{n}=1(20.0 \%)\end{array}$ & $\begin{array}{c}\text { Unknown, } n=5 \\
(100 \%)\end{array}$ & - & $0(0 \%)$ \\
\hline $\begin{array}{l}\text { Alexander, } \\
2007\end{array}$ & 10 & & $\begin{array}{c}\text { Unknown, } \mathrm{n}=10 \\
(100 \%)\end{array}$ & 5.3 & - \\
\hline $\begin{array}{l}\text { Modanlou, } \\
2009\end{array}$ & 87 & & $\begin{array}{c}\text { Unknown, } \mathrm{n}=87 \\
(100 \%)\end{array}$ & $4.3(2.6)$ & $1(1.1 \%)$ \\
\hline
\end{tabular}

DD: deceased donor; DM: diabetes mellitus; HTN: hypertension; KTX: kidney transplant; LAGB: laparoscopic adjustable gastric band; LD: living donor; LSG: laparoscopic sleeve gastrectomy; PCKD: polycystic kidney disease; RYGB: Roux-en-Y gastric bypass. 